\title{
Primary Characterization of SARS Coronavirus Strain Frankfurt 1
}

\author{
A. P. Agafonov, A. A. Gus'kov, V. A. Ternovoi, E. I. Ryabchikova, A. G. Durymanov, \\ I. V. Vinogradov, N. L. Maksimov, G. M. Ignat'ev, E. A. Nechaeva, \\ and Corresponding Member of RAS S. V. Netesov \\ Received August 7, 2003
}

Severe acute respiratory syndrome (SARS) or atypical pneumonia was first diagnosed in Guangdong Province (China) in November 2002. According to WHO data, patients with atypical pneumonia appeared in 29 countries throughout the world by mid-2003. By June 2003, the total number of affected persons reached 8435, including 789 lethal cases [1]. The SARS causative agent was found to be a virus from genus Coronavirus of the Coronaviridae family [2]. Members of genus Coronavirus have been known for a long time. These are enveloped, positive-stranded RNA viruses that cause human and animal diseases [3, 4]. However, such a severe coronavirus infection have been previously extremely rare in humans. Because of the high risk of atypical pneumonia epidemic, the properties of SARS virus, a new member of this genus, are being studied extensively [5-8].

Our study was the first to analyze the basic properties of SARS virus, which permitted the creation of an original diagnostic test system based on RT-PCR and development of the classical RTHA diagnosticum, a "gold standard" for many infections. The new data on the virus culture properties make it possible to develop attenuated and inactivated vaccines, as well as to screen medicinal preparations.

The strain Frankfurt I of SARS virus was kindly provided by Dr. H. W. Doerr (Institute of Medical Virology, Frankfurt am Main, Germany). To study specific reproduction of SARS virus, it was cultivated in the transpantable cell lines Vero, 293, and 4647, as well as in the diploid cell line L-68 at a multiplicity of inoculation of $1: 10$. Changes in the monolayer depended on the cell line. In the cultures of Vero and 4647, the cells became round-shaped, and the monolayer slipped down on the second and third days after the inoculation, respectively. Similar cell damage has was described previously, when coronavirus was isolated from a colt [9]. The virus cultivation in cells 293 and L-68 led to changes in the monolayer on the third day, specifically,

Vector State Scientific Center of Virology and Biotechnology, Kol'tsovo, Novosibirsk oblast, 630559 Russia the disruption of the monolayer because of local cell lysis. Virus reproduction in cells was monitored by the RT-PCR method. Amplification was conducted as described previously [7] using the BNIinS and BNIinAs primers developed in the Institute of Tropical Medicine (Hamburg, Germany) [7]. The samples taken from all passages of the cells studied were found to contain the SARS-virus RNA.

Electron-microscopic examination revealed coronavirus reproduction in cultures of the Vero and 293 lines on the second and third days after inoculation, respectively. The endoplasmic reticulum of the infected cells contained particles with a morphology typical of coronavirus: long surface projections, a coiled nucleoid, and an electron-transparent core (Fig. 1a). Virion accumulation was also observed in the perinuclear space and smooth-membrane vacuoles. In cells of the Vero culture, the content of viral particles was significantly higher than in cells of line 293 . In the culture medium, spherical viral particles 80-90 nm in size with specific surface projections forming a "crown" were revealed by negative staining (Figs. 1b, 1c). Thus, SARS virus morphology was typical of coronavirus in both ultrathin sections and suspension [10].

After cultivation of SARS virus, virus-containing culture medium (VCCM) was collected, and virus titer was determined on the basis of the cytopathological effect on the Vero cell monolayer. The results shown in the table suggest that the SARS virus reproduction in Vero cells was more efficient than in cells 293, L-68, and 4647. The rate of virus reproduction in Vero cells was also higher. The cell cultures L-68 and 4647 are approved for the use as substrate cultures for manufacturing vaccine preparations; line 293 is currently undergoing evaluation at the Tarasevich Institute of Certification and Control. None of the cultures used in this study contained contaminating viruses, mycoplasmas, and bacteria, and were not tumorigenic. Species affiliation of these cultures was confirmed by karyological analysis. Nevertheless, virus adaptation to these cell cultures, selection for nutrient media and cultivation conditions are required to develop an anti-SARS vaccine.

Coronaviruses are known to contain the protein esterase-hemagglutinin, which gives the virus the abil- 

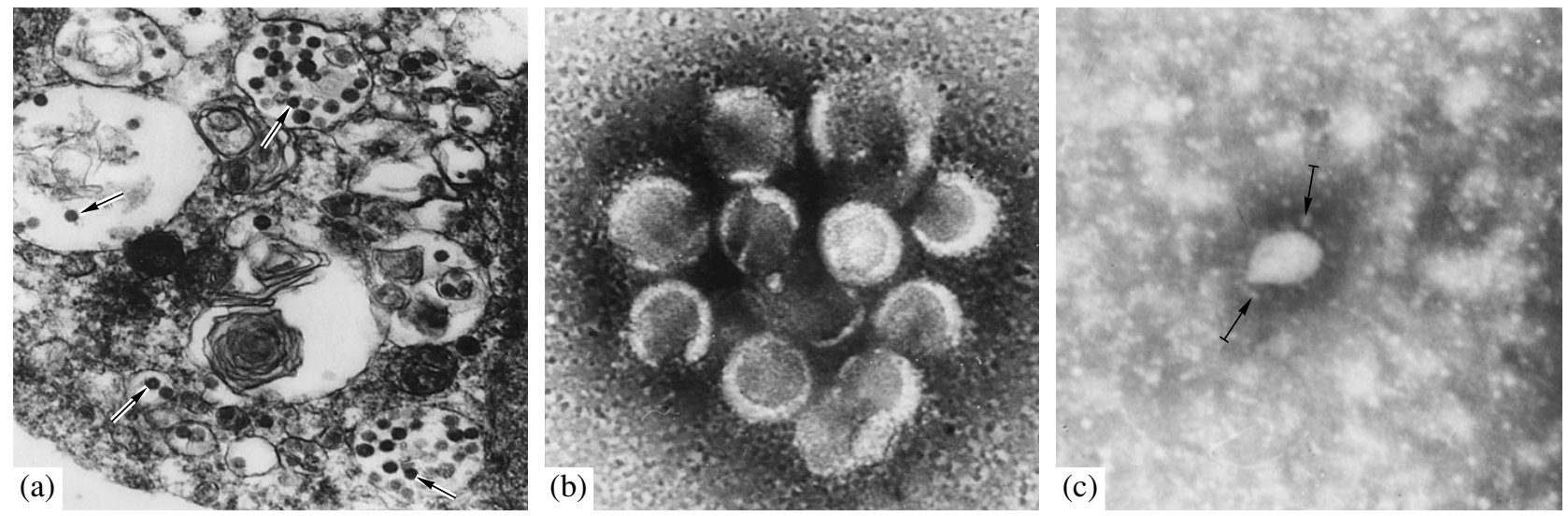

Fig. 1. (a) SARS virus particles in Vero cell culture. Ultrathin section. Magnification, 30000×. Arrows indicate viral particles. (b) SARS virus particles in culture medium. Negative staining with uranyl acetate. Magnification, $150000 \times$. (c) A particle of SARS virus in culture medium. Negative staining with uranyl acetate. Magnification, $120000 \times$. Arrows indicate peplomers.

ity to agglutinate erythrocytes of various animal species $[11,12]$. No data on the hemagglutinating properties of SARS coronavirus had been reported previously. The hemagglutination reaction was conducted as described previously [13]. We found that the virus is capable of agglutinating human, rat, and guinea pig erythrocytes and it poorly agglutinates mouse erythrocytes (line $\mathrm{BALB} / \mathrm{c})$. This virus was incapable of agglutinating monkey (Macaca mulatta), chicken, goose, or sheep erythrocytes.

Analysis of the virus properties showed that it was neutralized by a cattle serum (Novosibirsk Regional Veterinary Laboratory) (RTHA titer, $1: 128$ ) at a dilu- tion of $1: 32$. The reaction was conducted using a modified technique described in [14].

To confirm the genetic origin of the virus studied, RNA was isolated from a mixture of VCCM and infected cells Vero (the third passage), and RT-PCR was performed. The original diagnostic primers for a region of polymerase orf $1 \mathrm{~b}$ gene were used in this reaction. Alignment of the DNA sequences for all known variants of SARS virus was conducted. Using Oligo 6.31 software (Molecular Biology Insights, Inc. 2000), the following primers were selected in the regions containing no nucleotide substitutions:

\section{5'-TTGGAACAAGCAAGTTTTACGGTG-3' SARS(15122)F, 5'-ACAACGGCATCATCAGAAAGAATC-3' SARS(15624)R, 5'-GACATACCAGGCATACCAAAGGAC-3' SARS(18076)F, 5'-TGAAGTAGAAAAGCAAGTTGCACG-3' SARS(18594)R.}

Primer coordinates on the genomic sequence of SARS virus are indicated in parentheses.

A 518-bp PCR-fragment was obtained using the pair of primers SARS(18076)F and SARS(18594)R. A 502-bp PCR-fragment was obtained using another pair of primers, SARS(15122)F and SARS(15624)R. Sequencing of both amplified fragments using a Beckman CEQ2000XL DNA Analysis System (Beckman Coulter) was conducted as recommended by the manufacturer. Comparison of nucleotide sequences of the amplified products showed that the fragment of SARS viral genome studied did not differ from the sequences previously included into the GenBank (GenBank-Ay 291315). Thus, the isolated RNA belong to SARS virus, and the above primers were used in positive control for the test-system VectoSARS-RNA-ampli-100 developed in the Vector State Center of Virology and Biotechnology. In addition, the obtained data testify to the genetic stability of the viral genome region that encodes polymerase orf $1 \mathrm{~b}$ during at least three passages of the virus.

The 72-h virus culture of the second passage, which was grown in Vero cells, has been lyophilized and stored as a strain of SARS virus in the collection of microorganisms of the Vector State Center of Virology and Biotechnology (Kol'tsovo, Novosibirsk oblast, Russia). Virus-containing liquid was mixed with sucrose-gelatin stabilizer at a ratio of $1: 1$, and $0.2-\mathrm{cm}^{3}$ samples were frozen in ampoules in a refrigerator for a day at $-80^{\circ} \mathrm{C}$. Afterwards, lyophilization was conducted for $18 \mathrm{~h}$ with a gradual increase in temperature to $20^{\circ} \mathrm{C}$. Then, the ampoules containing dry material were sealed and stored at $-20^{\circ} \mathrm{C}$ in the collection of microorganisms of the Vector State Center of Virology and Biotechnology (no. V-326). The virus titers were 
Cultivation of SARS virus

\begin{tabular}{c|c|c|r|r}
\hline \multirow{2}{*}{$\begin{array}{c}\text { Cell } \\
\text { culture }\end{array}$} & \multirow{2}{*}{$\begin{array}{c}\text { Passage } \\
\text { no. }\end{array}$} & \multicolumn{3}{|c}{$\begin{array}{c}\text { Virus titer }\left(\mathrm{CPE}_{50} / \mathrm{ml}\right) / \text { time from } \\
\text { the beginning of incubation, } \mathrm{h}\end{array}$} \\
\cline { 3 - 5 } & & 24 & 48 & 72 \\
\hline L-68 & 1 & n.d. & $8.75 \times 10^{1}$ & $2.0 \times 10^{3}$ \\
4647 & 1 & $3.5 \times 10^{1}$ & $4.5 \times 10^{3}$ & $1.25 \times 10^{4}$ \\
Vero & 1 & n.d. & $1.5 \times 10^{4}$ & $3.25 \times 10^{6}$ \\
& 2 & $3.75 \times 10^{2}$ & $6.25 \times 10^{4}$ & $5.0 \times 10^{6}$ \\
& 3 & $6.0 \times 10^{1}$ & $1.75 \times 10^{4}$ & $8.5 \times 10^{5}$ \\
293 & 1 & $6.75 \times 10^{1}$ & $4.25 \times 10^{3}$ & $1.0 \times 10^{4}$ \\
& 2 & $3.0 \times 10^{1}$ & $8.5 \times 10^{2}$ & $6.5 \times 10^{3}$ \\
\hline
\end{tabular}

Note: n.d., virus titer was not determined.

$5.0 \times 10^{6}$ and $2.5 \times 10^{6} \mathrm{CPE}_{50} / \mathrm{ml}$ before and after lyophilization, respectively.

\section{ACKNOWLEDGMENTS}

We are grateful to our colleagues from the Vector State Center of Virology and Biotechnology V.B. Loktev for the help in the work organization, L.B. D'yachkova for technical assistance in experiments with the virus, O.A. Agafonova for the help with the publication of the manuscript, I.A. Razumov, A.A. Sergeev, and V.N. Petrishchenko for providing us with lines 293 and 4647, V.N. Bondarenko for providing us with animal erythrocytes, Yu.A. Gorbunov for the synthesis of primers used in RT-PCR, and to the head of the Virology Department, Novosibirsk Regional Veterinary Laboratory V.I. Aksenov for providing us with the serum against coronavirus KRC. We express special gratitude to Dr. H.F. Rabenau (Institute of Medicinal Virology, Frankfurt am Main, Germany) without whose assistance this study would be impossible.

\section{REFERENCES}

1. Update: Severe Acute Respiratory Syndrome: United States, June 11, 2003, vol. 52 of Morbidity and Mortality Weekly Reports, 2003.

2. Rota, P., Oberste, S., Monroe, S., et al., Science, 2003, vol. 300, pp. 1394-1399.

3. Robb, J.A. and Bond, C.W., in Comprehensive Virology, New York: Plenum, 1979, vol. 14, pp. 193-247.

4. Wege, H., Siddel, S., and Ter Meulen, V., Curr. Topics Microbiol. Immunol., 1982, vol. 99, pp. 165-200.

5. Lee, N., Hui, D., Wu, A., et al., New Engl. J. Med., 2003, vol. 348, pp. 1986-1994.

6. Poutanen, S.M., Low, D.E., Henry, B., et al., New Engl. J. Med., 2003, vol. 348, pp. 1995-2005.

7. Drosten, C., Günther, S., Preiser, W., et al., New Engl. J. Med., 2003, vol. 348, pp. 1967-1976.

8. Peiris, J.S.M., Lai, S.T., Poon, L.L.M., et al., Lancet, 2003, vol. 361, pp. 1319-1325.

9. Guy, J.S., Breslin, J.J., and Breuhaus, B., et al., J. Clin. Microbiol., 2000, vol. 38, pp. 4523-4526.

10. Ksiazek, T.G., Erdman, D., Goldsmith, C.S., et al., New Engl. J. Med., 2003, vol. 348, pp. 1953-1966.

11. King, B. and Brian, D.A., J. Virol., 1982, vol. 2, pp. 700707.

12. Dea, S., Verbeek, A.J., and Tijssen, P., J. Virol., 1990, vol. 64, pp. 3112-3118.

13. Tsunemitsu, H., El-Kanawati, Z.R., Smith, D.R., et al., J. Clin. Microbiol., 1995, vol. 33, pp. 3264-3269.

14. Guy, J.S., Breslin, J.J., Breuhaus, B., et al., J. Clin. Microbiol., 2000, vol. 38, pp. 4523-4526. 